\title{
Developing Entrustable Professional Activities for Doctoral Graduates in Health Professions Education: Obtaining a National Consensus in Iran
}

\section{Reza Zaeri}

Tehran University of Medical Sciences

Roghayeh Gandomkar ( $\nabla$ rgandomkar@tums.ac.ir)

Tehran University of Medical Sciences

\section{Research Article}

Keywords: Entrustable Professional Activities, Health Professions Education, Doctoral program

Posted Date: January 31st, 2022

DOI: https://doi.org/10.21203/rs.3.rs-1305817/v1

License: (c) (1) This work is licensed under a Creative Commons Attribution 4.0 International License.

Read Full License 


\section{Abstract \\ Background}

The number of doctoral programs in health professions education (HPE) is expanding. Entrustable professional activities (EPAs) can be a mechanism to define the expected activities of the HPE doctorate to inform training and assessment processes. The purpose of this study was to develop and reach a consensus on EPAs for HPE doctoral graduates.

\section{Methods}

We used a modified Nominal Group Technique (NGT) to elicit EPA titles followed by two rounds of a modified Delphi survey to seeking consensus on the EPAs among groups of experts (HPE doctoral graduates and Board of Health Professions Education Examiners members) at the national level in Iran between July 2019 and July 2020.

\section{Results}

A total number of 92 initial EPA titles, which emerged from brainstorming in the NGT meeting, was reduced to 27 titles during the abstraction process. The final EPA framework consisted of 24 EPA titles with descriptions, arranged in three categories: Research and scholarship (6 EPAs); Educational development (11 EPAs); and Educational management (7 EPAs). All final EPAs scored $\geq 80 \%$ agreement at the national level.

\section{Conclusions}

The proposed EPAs framework can be used to improve the HPE doctorate training and to inform employment decisions. A future international consensus procedure could use these EPA outcomes as a starting point.

\section{Background}

The number of doctoral degree-awarding programs in health professions education (HPE) is progressively expanding [1]. Many academic institutions, HPE scholarship units, professional associations and health care delivery centers hire graduates with such advanced degree [2] to support innovations in curriculum, optimizations in teaching and learning, implementation of programmatic assessment and initiatives in quality assurance, as well as engagement in scholarship activities, resulting in publication [3]. While there may be a general understanding of what these scholars can be employed for, activities that can be expected from doctoral graduates in HPE have not been defined. 
Doctoral programs in HPE generally adopted traditional North American model which require coursework, research, publications, and a dissertation. In several other programs, students could acquire a PhD by choosing to specialize in HPE under the broader programs of higher education, psychology or sociology. There are also some programs that did not follow a structured curriculum, but candidates complete a number of publishable research projects through supervision and apprenticeships [4]. The most important goals of the doctoral programs in HPE are to prepare students to conduct robust research, to pursue a teaching career at academic institutions and to identify complex problems in educational systems and produce innovative solutions aimed to improve the quality of life at individual, organizations, and society levels [5-8].

The literature about HPE doctoral programs is mainly focused on listing the institutions that offer a formal or less structured doctoral programs [1], and providing basic information about the role of programs and their various options [9], organizational structure [10], the process of supervision and quality of research [11]. Other studies provided standards for PhD dissertations in HPE [12] or proposed tips for studying a PhD in HPE $[6,13]$. One paper compared the instructional content of Master and PhD programs in HPE and mapped the links between the content of HPE programs and CPD roles and responsibilities [14]. Despite the growing desire for recruitment of HPE doctoral graduates, the published literature does not necessarily address the expected activities that graduates in HPE doctorate should be ready to perform.

The Entrustable Professional Activities (EPAs) framework may be a mechanism to define the activities the HPE doctorate may be expected to do. EPAs describe activities of a profession that are performed by qualified persons, independently and proficiently; requiring integrated competencies in different areas in order to perform activities effectively [15]. The description of EPAs can guide doctoral supervisors as well as trainees concerning the extent, specificity, and context of the training and assessment, and inform administrators, graduates and future employers about the expected activities [16].

There is a large body of literature on development and implementation of EPAs in health care education [17] including residency $[18,19]$ and undergraduate medical education programs [20]. The EPAs of these medical training programs are mainly concentrated on different aspects of practice in clinical environment while activities related to doctoral programs are concerned with the requirements for academic environment such as research and teaching. There is also a growing number of studies on describing EPAs for other areas of medical education such as translational scientists [21], simulation leaders [22] and program directors [23]. More recently, EPAs have been described for university teachers in the health professions $[24,25]$ in the context of faculty development for basic teaching activities [26] and small group facilitation [27, 28]. Mink et al. elaborated an EPA 'Scholar', to describing the competencies needed for residents to conduct scholarly projects in medicine [29]. We found only one study related to EPAs in HPE scholarship. University of Michigan Medical School developed a set of 20 EPAs for a competency-based Master program in HPE and incorporated it in all learning experiences [30] and in the assessment procedures for the Master candidates [31]. We did not find similar approaches in HPE doctoral programs. Given the lack of studies in doctoral training and distinctive features of this program, 
the purpose of this study is to develop and reach consensus on EPAs for doctoral graduates in HPE in Iran.

The first doctoral program started in 2010 in Iran. Ten years later, five Departments for HPE offered this degree around the country. These doctoral programs follow the North American model and the goals of the programs have been defined (the same for all five departments) as designing and conducting rigorous research projects in HPE, promoting innovations and development projects, supporting the process of change, providing consultations at different levels and Human Resource Development. Graduates are mostly employed in HPE scholarship units with the expectation of undertaking a range of responsibilities including education development projects, teaching and performing research. In 2015, a national project was started to develop the competency framework for doctoral graduates in HPE to guide HPE doctoral curriculum [32]. Following that, the current study aimed at developing EPAs to direct the learning and assessment, and to provide evidence of competence. The proposed EPA framework could be applied in other HPE doctoral programs with similar aims and structure.

\section{Methods}

\section{Setting and participants}

This study was conducted in the context of doctorate programs in HPE in Iran between July 2019 and July 2020. Participants in our study were doctoral graduates in HPE and members of Board of HPE Examiners. Eleven doctoral graduates in HPE were invited for the first phase of the study via email. The graduates were selected based on their continued activity in the field of HPE after graduation. We deliberately recruited graduates from different work settings to ensure variation in ideas. All eleven members of Board of HPE Examiners and forty doctoral graduates in HPE were requested to complete an online questionnaire.

\section{Procedure}

The study was performed in two major phases: modified Nominal Group Technique (NGT) and modified Delphi study.

\section{Phase 1: Nominal Group Technique}

We used a modified NGT to elicit EPA titles (a general item in a job description and not as specific for a person or a context) of doctoral graduates in HPE in July 2019. The NGT facilitates the participation of all group members to generate fresh ideas through a brainstorming format [33]. Since the concept of EPAs is new to the training of doctorate in HPE, we held a NGT session to develop an initial list of EPA titles to include in a Delphi process.

The meeting was led by three moderators, two of whom were the authors on this paper. The third moderator was the previous head of the Department of HPE at TUMS with the experience of teaching 
HPE doctoral students. The meeting was lasted four hours. The first phase of NGT meeting started with providing background information; a brief description of the NGT process (i.e. silent brainstorm ideas, present and record ideas, and clarify and prioritize ideas) followed by an introduction to the necessity of defining EPAs, its definition and its difference with competencies. Competencies are descriptors of individual graduates while EPAs are descriptors of work. EPAs usually entail multiple competencies in an integrative way and they are a means to translate competencies into workplace [34]. This was followed by an open conversation to raise questions and concerns about the EPAs and project. Two questions were then projected on a screen: "What do doctoral graduates in HPE do after graduation?" and "Can these activities be captured in EPAs?" Participants were then asked to write down their proposed EPAs in silence. In the third phase, each participant shared one EPA from their list with the group in a round-robin format. Participants took turns, not allowing to name or react to any previously mentioned items. This cycle continued until no new ideas emerged. All mentioned EPAs were directly typed by one author (RZ) and projected on the screen, allowing the whole group to read a growing list of EPAs. After that, with the assistance of the moderators, participants discussed the list of EPAs that were not clear to them and made clarifications. Appreciating the participants' limited time, other steps were performed off-site.

After meeting, the authors of this paper reviewed the initial list of EPAs, combined similar EPAs and afterwards grouped related EPAs into categories and selected a label for each category. We sent the EPAs titles to the NGT participants digitally and asked them to provide their qualitative comments and to suggest more abstraction if needed. This clarification and abstraction phase with participants was repeated twice. After the final refinement, we asked participants to rank the EPAs on a Likert scale, being 1 "not very important" for doctoral graduates in HPE and 5 "very important". Voting results were then summed across participants.

\section{Phase 2: modified Delphi study}

We performed two rounds of a modified Delphi survey to seek consensus on the EPA titles among wider groups of experts at the national level between December 2019 and July 2020. The Delphi technique uses multiple rounds to reach agreement on specific items among geographically dispersed participants [33]. In Delphi round 1, EPA titles obtained from NGT were sent to the study panels digitally. Participants were asked to (1) rate the "importance" of each EPA based on a Likert scale from 1 to 5 , where 1 was "not very important" and 5 was "very important", (2) check for modifications or changes needed for each EPA and (3) identify ignored titles of EPAs. Authors participated in one meeting of the Board and explained the aim and method of the study and invited members to participate. Next, participants were given the opportunity to raise concerns and questions, and receive clarifications. There were 51 HPE doctoral graduates at the time of this study. Eleven were invited for NGT meeting and the rest for the Delphi rounds. Graduates were invited via email, confirmed by a personal contact.

EPA titles were modified based on the quantitative and qualitative results of the first Delphi round. All qualitative comments were reviewed by the authors, which led to major revisions in the general structure and wording of the titles. A new title was added to the list if two participants mentioned it. Modifications were made even if EPAs scored $\geq 80 \%$ agreement if suggested by at least 2 members of the panel or 
after consensus discussion between the researchers reviewing the comments. By reviewing the comments, the authors concluded that developing the EPAs descriptions would make them more clear. Therefore, in the next step, one author (RZ) elaborated the EPA descriptions for each of the EPA titles based on the recommended "features" provided by ten Cate \& Taylor (2020) [16]. Descriptions of EPAs were discussed in a panel of 4 specialists in HPE. Finally, another author (RG), with experience in HPE training and research, reviewed and edited the descriptions. The elaboration process led to further combining EPA titles with overlapping content.

During the Delphi round 2, panel members were provided EPAs descriptions including title, specifications and limitations and potential risks in case of failure. Experts were told the mean responses from the first round. Because we had made major revisions in EPA titles, we supplied all EPAs in the second phase. Participants were asked to rate the "importance" of each EPA for doctoral graduates in HPE based on a Likert scale from 1 to 5 , where 1 was "not very important" and 5 was "very important". There was a box for each EPA title and descriptions for comments. There was no need for a third Delphi round since all EPAs fulfilled the agreement criteria in the second round. Refinement was made in EPA titles and descriptions based on the qualitative comments.

\section{Data analysis}

Descriptive statistics were calculated using IBM SPSS statistics 23 including frequency, mean (M) and standard deviation (SD). We defined consensus as $\geq 80 \%$ agreement for a rating of 4 (moderately important) and 5 (absolutely important).

\section{Results}

Nine of eleven doctoral graduates in HPE agreed to participate in the NGT meeting. There were 34 (response rate $=0.85$ ) and 26 (response rate $=0.65$ ) doctoral graduates in HPE who completed the survey in Delphi round 1 and 2, respectively. Nine (response rate= 0.82) members of Board of Health Professions Education Examiners participated in two rounds of Delphi. In all, 73\% (38 out of 52) of study participants were female. The largest numbers of participants $83 \%$ (41 out of 52 ) worked in HPE scholarship units.

\section{Phase 1: Nominal Group Technique}

A total numbers of 92 initial EPA titles emerged from brainstorming and clarification in NGT meeting and reduced to 75 titles in five areas of consultation, research and scholarship, education, management and evaluation during abstraction by research team and then to 27 titles during the iterative abstraction process by the NGT participants. All 27 EPA titles scored 100\% agreement throughout the voting phase. The number of EPAs in each domain were: Consultation $(n=6)$, Research and scholarship $(n=5)$, Education $(n=7)$, Management $(n=5)$ and Evaluation $(n=4)$.

\section{Phase 2: modified Delphi study}


The titles of EPAs, levels of agreement as well as means and standard deviations per EPA of the first Delphi round are demonstrated in Supplemental Table 1. Out of all EPAs, 16 scored $\geq 80 \%$ agreements with 10 showing 100 percent agreements. The remaining 11 EPAs scored slightly lower than the threshold (78\% agreement). Based on the qualitative comments, general structure of the EPA framework was adapted and the EPAs rearranged in three categories: Research and scholarship (6 EPAs), Educational development (11 EPAs) and Educational management (7 EPAs). Table 1 provides a map of the changes made in general structure of the EPAs. Overall, 4 EPAs were deleted, 5 were merged ( 3 combined and shaped one new EPAs, and 2 others each merged into one existing EPA), one split into 2 EPAs, 4 new EPAs emerged and as a results, 24 EPAs developed. Deleted EPAs demonstrated good agreement in terms of importance yet based on the comments they were nested in other EPAs and seemed redundant. The research and scholarship domain showed the least changes. 
Table 1

Changes in general structure of EPAs based on the results of the first Delphi round

\begin{tabular}{|c|c|c|c|}
\hline \multirow[t]{2}{*}{ EPAs } & & \multicolumn{2}{|l|}{ New structure } \\
\hline & & EPA number & Domain \\
\hline \multirow[t]{6}{*}{ Domain 1: Consultation } & EPA 1 & EPA 6 & Research \& scholarship \\
\hline & EPA 2 & Merged, EPA 17 & Educational development \\
\hline & EPA 3 & Merged, EPA 17 & - \\
\hline & EPA 4 & Merged, EPA 17 & - \\
\hline & EPA 5 & EPA 24 & Educational management \\
\hline & EPA 6 & EPA 12 & Educational development \\
\hline \multirow[t]{5}{*}{ Domain 2: Research \& scholarship } & EPA 7 & EPA 1 & Research \& scholarship \\
\hline & EPA 8 & Merged, EPA 1 & - \\
\hline & EPA 9 & EPA 2, EPA 3 & Research \& scholarship (2) \\
\hline & EPA 10 & EPA 4 & Research \& scholarship \\
\hline & EPA 11 & EPA 5 & Research \& scholarship \\
\hline \multirow[t]{7}{*}{ Domain 3: Education } & EPA 12 & EPA 11 & Educational development \\
\hline & EPA 13 & EPA 9 & Educational development \\
\hline & EPA 14 & Merged, EPA 8 & - \\
\hline & EPA 15 & Deleted & - \\
\hline & EPA 16 & EPA 8 & Educational development \\
\hline & EPA 17 & EPA 20 & Educational management \\
\hline & EPA 18 & EPA 10 & Educational development \\
\hline \multirow[t]{5}{*}{ Domain 4: Management } & EPA 19 & Deleted & - \\
\hline & EPA 20 & EPA 18 & Educational management \\
\hline & EPA 21 & Deleted & - \\
\hline & EPA 22 & Deleted & - \\
\hline & EPA 23 & EPA 23 & Educational management \\
\hline \multirow[t]{3}{*}{ Domain 5: Evaluation } & EPA 24 & EPA 14 & Educational development \\
\hline & EPA 25 & EPA 16 & Educational development \\
\hline & EPA 26 & EPA 15 & Educational development \\
\hline
\end{tabular}




\begin{tabular}{|llll|}
\hline EPAs & & New structure & \\
\cline { 3 - 4 } & & EPA number & Domain \\
\hline EPA 27 & EPA 13 & Educational development \\
\hline New & EPA 7 & Educational development \\
\hline New & EPA 19 & Educational management \\
\hline New & EPA 21 & Educational management \\
\hline New & EPA 22 & Educational management \\
\hline
\end{tabular}

Insert Table 1.

Table 2 demonstrates the finalized titles of EPAs, levels of agreement, means and standard deviations for 24 EPAs rated during the second Delphi round. All EPAs scored $\geq 80 \%$ agreement, 7 with full agreement. The lowest consensus was on EPA 22 and 23 in the educational management domain. Revisions were made in EPA titles (minor refinement) and descriptions (major modifications) based on the qualitative comments. The final EPA descriptions (title, specifications and limitations, and potential risks in case of failure) can be found in Supplemental Table 2. 
Table 2

Levels of agreement, means and standard deviations per EPA of the second Delphi round

EPAs
EPA title
EPA importance

Level of Mean agreement

(\%)

\section{Domain 1: Research \& scholarship}

Domain 2: Educational Development

\begin{tabular}{ll|}
$\begin{array}{l}\text { EPA } \\
1\end{array}$ & $\begin{array}{l}\text { Identifying and translating educational needs to } \\
\text { research }\end{array}$ \\
\begin{tabular}{ll} 
EPA & Conducting and analyzing research \\
2 & \\
\hline $\begin{array}{l}\text { EPA } \\
3\end{array}$ & $\begin{array}{l}\text { Collaborating, directing and supervising research } \\
\text { teams }\end{array}$ \\
\hline $\begin{array}{l}\text { EPA } \\
4\end{array}$ & $\begin{array}{l}\text { Writing, publishing and communicating scientific } \\
\text { reports }\end{array}$ \\
\hline $\begin{array}{l}\text { EPA } \\
5\end{array}$ & Reviewing research and scholarship activities \\
\hline EPA & Consulting on research and scholarship in HPE \\
6
\end{tabular} \\
\hline
\end{tabular}

97

4.80 $(0.47)$

97

4.77

100

4.71

100

4.60

97

4.51

97

4.49
EPA Designing and conducting educational needs
7 assessment

97

4.54 $(0.60)$

EPA Developing, implementing and revising curricula 100

8 and educational programs

4.86

EPA Instructional designing for various teaching and 94

$9 \quad$ learning situations

4.83

EPA Designing and producing educational content in 100

10 HPE

4.69

$(0.57)$

EPA Teaching and facilitating in various educational

11 situations

94

4.66

EPA Mentoring stakeholder groups in HPE

91

4.71

12

$(0.51)$

EPA Reviewing educational materials and products 13

94

4.60

$(0.55)$

EPA Designing, implementing and revising student 100

4.54

14 assessment system

$(0.50)$

EPA Designing, implementing and revising the faculty 97

4.54

15 evaluation system

EPA Designing, implementing and revising quality

94

4.63

$(0.54)$ 


\begin{tabular}{|c|c|c|c|c|}
\hline \multirow[t]{2}{*}{ EPAs } & & \multirow[t]{2}{*}{ EPA title } & \multicolumn{2}{|c|}{ EPA importance } \\
\hline & & & $\begin{array}{l}\text { Level of } \\
\text { agreement } \\
\text { (\%) }\end{array}$ & $\begin{array}{l}\text { Mean } \\
\text { (SD) }\end{array}$ \\
\hline & $\begin{array}{l}\text { EPA } \\
17\end{array}$ & $\begin{array}{l}\text { Consulting on planning, teaching and learning } \\
\text { processes, and evaluation activities }\end{array}$ & 100 & $\begin{array}{l}4.66 \\
(0.53)\end{array}$ \\
\hline \multirow{7}{*}{$\begin{array}{l}\text { Domain 3: } \\
\text { Educational } \\
\text { Management }\end{array}$} & $\begin{array}{l}\text { EPA } \\
18\end{array}$ & $\begin{array}{l}\text { Analyzing, formulating and revising educational } \\
\text { policies }\end{array}$ & 97 & $\begin{array}{l}4.80 \\
(0.47)\end{array}$ \\
\hline & $\begin{array}{l}\text { EPA } \\
19\end{array}$ & Designing, implementing and evaluating reforms & 100 & $\begin{array}{l}4.71 \\
(0.45)\end{array}$ \\
\hline & $\begin{array}{l}\text { EPA } \\
20\end{array}$ & $\begin{array}{l}\text { Designing, implementing and evaluating personal } \\
\text { and professional support and development } \\
\text { programs }\end{array}$ & 91 & $\begin{array}{l}4.63 \\
(0.64)\end{array}$ \\
\hline & $\begin{array}{l}\text { EPA } \\
21\end{array}$ & $\begin{array}{l}\text { Managing organizational processes and } \\
\text { resources }\end{array}$ & 91 & $\begin{array}{l}4.49 \\
(0.65)\end{array}$ \\
\hline & $\begin{array}{l}\text { EPA } \\
22\end{array}$ & Managing and supervising projects & 89 & $\begin{array}{l}4.31 \\
(0.67)\end{array}$ \\
\hline & $\begin{array}{l}\text { EPA } \\
23\end{array}$ & $\begin{array}{l}\text { Analyzing the cost-effectiveness of practices and } \\
\text { interventions }\end{array}$ & 89 & $\begin{array}{l}4.43 \\
(0.77)\end{array}$ \\
\hline & $\begin{array}{l}\text { EPA } \\
24\end{array}$ & Consulting on management and leadership & 94 & $\begin{array}{l}4.57 \\
(0.60)\end{array}$ \\
\hline \multicolumn{5}{|c|}{ HPE stands for Health Profession Education } \\
\hline \multicolumn{5}{|c|}{ BEME stands for Best Evidence Medical Education } \\
\hline
\end{tabular}

Insert Table 2.

\section{Discussion}

To our knowledge, this is the first study to propose an EPA framework for doctoral graduates in HPE. Using NGT followed by modified Delphi methodology with doctoral graduates in HPE and members of Board of HPE Examiners, this study led to national consensus on 24 EPAs, categorized in research and scholarship (6 EPAs), educational development (11 EPAs) and educational management (7 EPAs). The number of EPAs in our proposed framework resembles the study on EPAs (20 title statements) for the Master's program in HPE at the University of Michigan Medical School [30] and are aligned with ten Cate's estimation (2013) that a maximum of 20 to 30 EPAs might be needed to cover graduate medical education training programs [34]. The recent report on EPAs in all Dutch specialty programs aligns with this notion as well [35]. The overlaps between our framework and EPAs proposed for the Master's program in HPE [30] may support common activities for HPE scholars. More specifically, the EPAs' dimensions of this study are in line with area of activities (i.e. research, teaching and educational development) that doctorate-trained HPE scholars are often involved in HPE scholarship units [36, 37]. 
Our participants were mostly the staff of HPE scholarship units and as expected they mentioned a range of activities for HPE professionals.

EPA statements related to the domain of research and scholarship had the highest level of agreement among participants in terms of importance. This domain underwent the least revisions during the consensus process. These findings are not surprising since research and scholarship activities serve as a core task during doctorate programs and it serves as a starting point of discussion across professionals [38]. Many of doctorate graduates are recruited in HPE scholarship units as research scientists and are engaged in a range of scholarly activities such as those we obtained in the research and scholarship domain. Etmanski et al (2020) showed that all HPE research scientists working in HPE scholarship units throughout Canada emphasized their career success in terms of a research-intensive pursuits resulted in peer-reviewed, evidence-based research manuscripts [39]. Similarly, in Iran, involving in research projects and publishing the results in peer-reviewed journals is one of the requirements for faculty promotion [40].

In the educational development domain, EPAs are associated with innovation and improvement in educational programs mainly by collaborating, advising and consulting on curriculum development or revision, instructional design, teaching and facilitation, resource material development, and design or redesign of student assessment and quality assurance system. The large number of EPAs proposed for this domain may be explained by the fact that many innovation projects are running at medical schools and other HPE setting (under the direction of HPE scholarship units) around the country [41] and this requires doctorate graduate involvement in the projects. In line with this explanation, Kahlke and Varpio (2019) demonstrated that HPE scholarship units' works were defined based on two dominant logics: research and service in the Canadian HPE context [42]. They showed that research or service activities were made important through their association with institutional orders and the context in which they were employed. The next step for our study would be the refinement and validation of EPAs based on the task analysis of HPE doctorate graduates in their work setting. We also recommend to explore the perceptions of experts and HPE doctorate graduates from other setting on the framework.

Although all the EPA statements developed in this study met the criteria for consensus, there was less agreement on several EPAs in the category of educational management and this domain underwent the most changes throughout the consensus phases. The reason may be that our respondents had experienced different job positions during their career in terms of involvement in administrative and leadership tasks and had different perceptions on educational management activities. If we asked participants to identify absolutely essential or desirable EPAs, we might observe more consensus for this question through this domain. Further research should be conducted to make distinctions between EPAs that are required or desirable doctorates in HPE to do without supervision. The emphasis on certain EPAs and the required level of unsupervised practice toward the end of training may differ between training programs and it can be another line for inquiry.

The methodology of the present study included a sequential multi-step approach of drafting preliminary EPAs and revising these EPAs via a modified Delphi approach that resembles previously published 
studies on developing EPAs. We incorporated the doctorate graduates' inputs in the processes of development in addition to experts' opinions (board members) which results in EPAs reflecting practice patterns of graduates. It is important particularly since the job description of HPE doctorate graduates is less studied. Another advantage of our study was that we devoted much time and effort on obtaining qualitative comments of participants and discussion with experts to enrich our data which is necessary for the HPE as an emerging field.

\section{Implications}

The developed EPA framework, titles with detailed descriptions for each EPA, has several implications into practice. First, it offers a way to translate competencies [32] to professional practice as they describe the activities that a competent HPE professional should be trusted to do. The next step for us would be to map the identified EPAs into relevant competency domains. Second, identified EPAs can be used to help program directors to implement structured training grounded in professional activities and to guide quality assurance. Additionally, it can be used as a tool for observing (direct observation of performance or indirect observations of evidence of achievement) the individual learning processes and for providing meaningful feedback based on these observations. The framework may also be used as a basis for making entrustment decisions and be ensured that doctoral trainees acquired competencies. Furthermore, the EPA framework allows HPE doctoral graduates to appreciate what is being asked of them when they are employed. It could also serve as a guide for the graduates to identify their learning gaps and cultivate their personal development plan. Lastly, the EPAs could offer those aspiring to obtain a doctoral degree with the extent and depth of the expected activities and deepen their understanding of

the professional role, and also could direct or orient employer who seeking to hire scholars with a doctoral degree in HPE.

\section{Limitations}

This study has limitations. First, it was developed in one country and given the dynamic nature of the field, it may not reflect particular activities expected from HPE doctorate graduates in other settings. Nevertheless, the EPA framework includes basic components that other programs can adapt to their training needs. Second, despite the diversity and broad experience of our expert group, it is possible that some items relevant to the work of HPE graduates are missing in our proposed EPA framework since the concept of EPA is new to HPE doctorate training. These descriptions should therefore be considered as a framework that can be adjusted over time if needed.

\section{Conclusions}

This study aimed at developing an EPA framework for doctoral graduates in HPE and at obtaining a national consensus in one country. Using NGT followed by modified Delphi methodology with doctoral graduates in HPE and members of Board of HPE Examiners, this study led to 24 EPAs, categorized in research and scholarship, educational development and educational management. The proposed EPAs framework can be used to improve the HPE doctorate training and to inform employment decisions. A 
future international consensus procedure could use these EPA outcomes as a starting point. The EPAs also need to be tested in the HPE field to ensure its practical feasibility.

\section{Abbreviations}

HPE

Health Professions Education

EPAs

Entrustable Professional Activities

$\mathrm{PhD}$

Doctor of Philosophy

CPD

Continuous Professional Development

\section{Declarations}

\section{Ethics approval and consent to participate}

We, authors confirm that all methods were carried out in accordance with Declaration of Helsinki guidelines and regulations. The Tehran University of Medical Sciences Research Ethics Committee granted ethical approval for the study (ID: IR.TUMS.MEDICINE.REC.1399.178). Informed verbal consent to participate was obtained from all project contributors. Verbal Consent obtained from the participants is accepted by the Tehran University of Medical Sciences Research Ethics Committee.

\section{Consent for publication}

Not applicable.

\section{Availability of data and materials}

All data generated or analysed during this study are included in this published article and its supplementary information files.

\section{Competing interests}

The authors declare that they have no competing interests.

\section{Funding}

This work was funded by the National Agency for Strategic Research in Medical Education. Tehran. Iran. under Grant number 981116 . The role of the funding body was in the design of the study and collection, analysis, and interpretation of data.

\section{Authors' contributions}


RG and RZ designed the study, gathered and analyzed the data, drafted and finalized the manuscript.

\section{Acknowledgements}

The authors would like to acknowledge Professor Olle ten Cate, Center for Research and Development of Education, University Medical Center Utrecht, Utrecht, the Netherlands for reviewing a previous version of the manuscript. We are grateful to all members of Board of HPE Examiners and doctoral graduates in HPE for their participation and active contribution to this research project.

\section{References}

1. Tekian A. Doctoral programs in health professions education. Med Teach. 2014;36(1):73-81.

2. Tekian A, Artino AR. AM last page: master's degree in health professions education programs. Acad Med. 2014;88(9):1399.

3. Artino JA, Cervero RM, DeZee KJ, Holmboe E, Durning SJ. Graduate programs in health professions education: preparing academic leaders for future challenges. J Grad Med Educ. 2018;10(2):119-122.

4. Cervero RM, Daley BJ. The need and curricula for health professions education graduate programs. New Dir Adult Cont Educ. 2018;2018(157):7-16.

5. Stewart D, Frasier H, Sims L, Denecke D. CGS Task Force Report on the Professional Doctorate. Washington, DC: Council of Graduate Schools. 2006.

6. Gill D, Griffin A, Woolf K, Cave J. Twelve tips for studying medical education at doctoral level. Med Teach. 2009;31(7):601-604.

7. Aiken JA, Gerstl-Pepin C. Envisioning the $\mathrm{EdD}$ and $\mathrm{PhD}$ as a partnership for change. Plann \& Chang. 2013;44(3):162-180.

8. Marusic M, Mimica M, Mihanovic F, Jankovic S. Doctoral degree in health professions: professional needs and legal requirement. Acta Med Acad. 2013;42:61-70.

9. Pan YJ, Lee LS. Who wants to enroll in health care PhD programs? An analysis of a nationwide graduate destination survey. J Chinese Med Assoc. 2012;75(6):286-291.

10. Leja JA, Wardley CS. Future trends in health care doctoral education. J Allied Health. 2002;31(4):227-231.

11. Pugsley L, Brigley S, Allery L, MacDonald J. Making a difference: Researching master's and doctoral research programs in medical education. Med Educ. 2008;42(2):157-163.

12. ten Cate O, Derese A, Durning SJ, O'Sullivan P. Excellence in PhD dissertations in health professions education: Toward standards and expectations. Med Teach. 2017;39(9):926-930.

13. Bryan B, Church HR. Twelve tips for choosing and surviving a PhD in medical education-a student perspective. Med Teach. 2017;39(11):1123-7.

14. Cervero RM, Artino AR Jr, Daley BJ, Durning SJ. Health professions education graduate programs are a pathway to strengthening continuing professional development. J Contin Educ Health Prof. 2017;37(2):147-51. 
15. ten Cate 0 . Entrustability of professional activities and competency-based training. Med Educ. 2005;39(12):1176-1177.

16. ten Cate 0 , Taylor $D$. The recommended description of an entrustable professional activity (AMEE guide 140). Med Teach. 2021; 43(10):1106-1114.

17. Shorey S, Lau TC, Lau ST, Ang E. Entrustable professional activities in health care education: a scoping review. Med Educ. 2019;53(8):766-777.

18. O'Dowd E, Lydon S, O'Connor P, Madden C, Byrne D. A systematic review of 7 years of research on entrustable professional activities in graduate medical education, 2011-2018. Med Educ. 2019;53(3):234-249.

19. Pinilla S, Lenouvel E, Strik W, Klöppel S, Nissen C, Huwendiek S. Entrustable professional activities in psychiatry: a systematic review. Acad psych. 2020;44(1):37-45.

20. Meyer EG, Chen HC, Uijtdehaage S, Durning SJ, Maggio LA. Scoping review of entrustable professional activities in undergraduate medical education. Acad Med. 2019;94(7):1040-1049.

21. Weggemans MM, Ter Haar NM, Prakken B, ten Cate O. Developing Entrustable Professional Activities for the Training of Translational Scientists: A Modified Delphi Study. Acad Med. 2021;96(10):14611466.

22. Gardner AK, Gee D, Ahmed RA. Entrustable professional activities (EPAs) for simulation leaders: the time has come. J Surg Educ. 2018;75(5):1137-1139.

23. Bing-You RG, Holmboe E, Varaklis K, Linder J. Is it time for entrustable professional activities for residency program directors? Acad Med. 2017;92(6):739-742.

24. Dewey CM, Jonker G, ten Cate 0 , Turner TL. Entrustable professional activities (EPAs) for teachers in medical education: Has the time come? Med Teach. 2017;39(8):894-896.

25. van Bruggen $L$, van Dijk EE, van der Schaaf M, Kluijtmans $M$, ten Cate O. Developing entrustable professional activities for university teachers in the health professions. Med Teach. 2021; doi.org/10.1080/0142159X.2021.1998402.

26. Walsh A, Koppula S, Antao V, Bethune C, Cameron S, Cavett T, et al. Preparing teachers for competency-based medical education: fundamental teaching activities. Med Teach. 2018;40(1):8085.

27. Iqbal MZ, Al-Eraky MM, AlSheikh MH. Designing entrustable professional activities for training health professional educators: A review of current practices. Med Sci Educ. 2018;28(4):797-802.

28. Iqbal MZ, Könings KD, Al-Eraky MM, van Merriënboer JJ. Entrustable Professional Activities for Small-Group Facilitation: A Validation Study Using Modified Delphi Technique. Teach Learn Med. 2021;33(5):536-545.

29. Mink RB, Myers AL, Turner DA, et al. Competencies, milestones, and a level of supervision scale for entrustable professional activities for scholarship. Acad Med. 2018;93(11):1668-1672.

30. Gruppen L, Burkhardt J, Fitzgerald J, Funnell M, Haftel HM, Lypson ML, et al. Competency-based education: programme design and challenges to implementation. Med Educ. 2016;50(5):532-539. 
31. Fitzgerald JT, Burkhardt JC, Kasten SJ, Mullan PB, Santen SA, Sheets KJ, et al. Assessment challenges in competency-based education: A case study in health professions education. Med Teach. 2016;38(5):482-90.

32. Keshmiri F, Gandomkar R, Hejri SM, Mohammadi E, Mirzazadeh A. Developing a competency framework for Health Professions Education at doctoral level: The first step toward a competency based education. Med Teach. 2019;41(11):1298-306.

33. Humphrey-Murto S, Varpio L, Gonsalves $C$, Wood TJ. Using consensus group methods such as Delphi and Nominal Group in medical education research. Med Teach. 2017;39(1):14-9.

34. ten Cate O. Nuts and bolts of entrustable professional activities. J Grad Med Educ. 2013;5(1):157158

35. de Graaf J, Bolk M, Dijkstra A, van der Horst M, Hoff RG, Ten Cate O. The Implementation of Entrustable Professional Activities in Postgraduate Medical Education in the Netherlands: Rationale, Process, and Current Status. Acad Med. 2021;96(7S):S29-35.

36. Varpio L, O'Brien B, Hu W, Ten Cate O, Durning SJ, van der Vleuten C, et al. Exploring the institutional logics of health professions education scholarship units. Med Educ. 2017;51(7):755-767.

37. O’Brien BC, Irby DM, Durning SJ, Hamstra SJ, Hu WC, Gruppen LD, et al. Boyer and beyond: an interview study of health professions education scholarship units in the United States and a synthetic framework for scholarship at the unit level. Acad Med. 2019;94(6):893-901.

38. Wilkes LM, Mohan S. Nurses in the clinical area: Relevance of a PhD. Collegian. 2008;15:135-141.

39. Etmanski B, Hamstra SJ, Varpio L. The sensemaking narratives of scientists working in health professions education scholarship units: The Canadian experience. Perspect Med Educ. 2020;9(3):157-65.

40. Sadeghi-Bazargani H, Bakhtiary F, Golestani M, Sadeghi-Bazargani Y, Jalilzadeh N, Saadati M. The research performance of Iranian medical academics: a National Analyses. BMC Med Educ. 2019;19(1).

41. Mortaz Hejri S, Mirzazadeh A, Mafinejad MK, Alizadeh M, Saleh N, Gandomkar R, et al. A decade of reform in medical education: experiences and challenges at Tehran University of Medical Sciences. Med Teach. 2018;40(5):472-480.

42. Kahlke R, Varpio L. Positioning the work of health professions education scholarship units: how Canadian directors harness institutional logics within institutional orders to convey unit legitimacy. Acad Med. 2019;94(12):1988-94.

\section{Supplementary Files}

This is a list of supplementary files associated with this preprint. Click to download.

- Supplementalfile.docx 